\title{
Heat and mass transfer in two-phase He I thermosiphon flow
}

\author{
B. Baudouy and D. Thomas
}

CEA/Saclay - DSM/DAPNIA/STCM, 91191 Gif-sur-Yvette Cedex, France

Phone: + 331 69084207, Fax: + 331 69086929, Email: baudouy@dapnia.cea.fr

\begin{abstract}
The paper presents the experimental set-up that is under construction at Service des Techniques de Cryogénie et Magnétisme located at Saclay. It describes the cryostat, the test section and the instrumentation that constitutes this experimental work.
\end{abstract}

\section{Introduction}

The study of heat and mass transfer in a two-phase He I thermosiphon flow is within the frame work of the CMS project. It is a part of the study that have been began to design the cryogenic cooling system of the 4 tesla superconducting solenoid for the CMS detector. Thus, this work is focused on steady state flow studies as well as the effects of thermal and dynamical perturbations of such flow. This study, essentially experimental; has the aim of measuring the different parameters of this type of cooling such as the total mass flow rate, the vapor mass flow rate, pressure and temperature differences, heat transfer coefficients and void fraction as a function of the heat flux deposited in the system. Moreover, experimental data will be compared with dynamical models.

\section{Experimental set-up and procedure}

\subsection{Cryostat}

The facility consists of a vertical oriented two meter long cryostat shielded by vacuum and nitrogen spaces. The experiment is mainly composed by a reservoir used as a liquid-vapor separator, a vertically oriented test section and its associated downward tube and vertical and horizontal radiation shields. Figure 1 presents a schematic of the facility. The $0.3 \mathrm{~m}$ high separator has a diameter of $0.45 \mathrm{~m}$ and serves as a liquid reservoir for the test section. The test section and the downward tube form a loop from the separator to create an open-end thermosiphon type of flow. Thermal shields are composed by two sets of radiation shields. The first one, made of aluminum, covers entirely the separator, the test section and the downward tubing and it is cooled down by helium vapor flowing out of the separator during the test. The second one is made of two copper horizontal shields. The vapor mass flow rate is measurement at room temperature with a Brooks ${ }^{\circledR}$ flow-meter up to $4 \mathrm{~g} / \mathrm{s}$.

The experimental procedure can be described as follow: After filling up the reservoir and regulating the pressure above the liquid, heaters, located on the test section, are energized to provide the same heat flux density. After attaining steady-state regime, the measurement of the different parameters is controlled by a computer via a Labview ${ }^{\circledR}$ program through 32 channels data acquisition at $10 \mathrm{kHz}$ by channels. As a function of the pressure, temperature in the separator, that we call initial pressure and temperature, $\mathrm{p}_{\mathrm{i}}$ and $\mathrm{T}_{\mathrm{i}}$, and the heat flux density, the different parameters are acquired. The initial pressure is measured by a room temperature Yokogawa ${ }^{\circledR}$ absolute pressure sensor. The total mass flow rate, $\dot{M}$, determined with a venturi flow meter, the vapor flow rate, $\dot{M}_{v}$ and the test section pressure drop, measured by cold temperature pressure sensor are the dynamical flow parameters. From the determination of the mass flow rates, the flow quality can be determined as 
$\chi=\frac{\dot{\mathrm{M}}_{\mathrm{v}}}{\dot{\mathrm{M}}}$

With the electron source void fraction meter, that is under development at STCM, the determination of flow quality and the void fraction, a will allow to compare the experimental results with the different dynamical model such as the homogeneous model, the separated phase model or the drift-flux model. Two-phase friction factor will be investigated through pressure drop measurement along the length of the heated section. The heat transfer coefficient will serve to investigate heat transfer correlation in such a flow.

\subsection{Test section}

The test section is a $14 \mathrm{~mm}$ inner diameter copper tube and its thickness is $1 \mathrm{~mm}$. The heated length is $1.25 \mathrm{~m}$ long. It is connected to the loop and to the phase separator by metal joint connections. The instrumentation is composed of heaters, temperature sensor, pressure drop measurement, a heat transfer coefficient measurement cell and in near future a void fraction meter.

Two heaters made of thermocoax ${ }^{\circledR}$ heating wire are soft soldered to the cooper tube and cover half of the tube length. They resistance is approximately $20 \mathrm{O}$ and the maximum power allowed is over $100 \mathrm{~W}$. They are energized separately to investigate the effect on fully heated tube and partially heated tube.

Three germanium sensor are placed along the length of the test section inserted in copper sensor older silver brazed to the copper tube. The temperature measured by this system is representative of the inner wall temperature and a fine analysis is necessary to determine this temperature.

\subsection{Instrumentation}

\subsubsection{Mass flow-meters}

Two mass flow meters are used in this experiment, a gas flow meter at room temperature that measure the vapor mass flow rate and a Venturi flow meter that measures the liquid mass flow rate (i.e. total mass flow rate).

The gas flow meter is a commercial flow meter capable of measuring $4.2 \mathrm{~g} / \mathrm{s}$ of $\mathrm{He}$ gas at room temperature with a precision of $1 \%$.

The liquid mass flow meter is a $0.4 \mathrm{~m}$ long Venturi with an entry inner diameter of $40 \mathrm{~mm}$ and neck diameter of $10 \mathrm{~mm}$. It will be instrumented with Validyne pressure sensor. The determination of the mass flow rated will be within $10 \%$ precision. With the precision of the pressure sensors, the range of this Venturi is starting from $0.5 \mathrm{~g} / \mathrm{s}$ and stops at $20 \mathrm{~g} / \mathrm{s}$ due to the configuration of the facility. At such a high mass flow rate, one have to notice that the pressure drop due to the Venturi itself is $2 \%$ of the driving pressure drop.

\subsubsection{Pressure difference measurements}

The pressure differences are measured by Validyne pressure sensors DP10-20 (range of 0.87 $\mathrm{KPa}$ ) and DP10-22 (range of $1.4 \mathrm{KPa}$ ) that are calibrated to give a precision of $\pm 2 \mathrm{~Pa}$. 


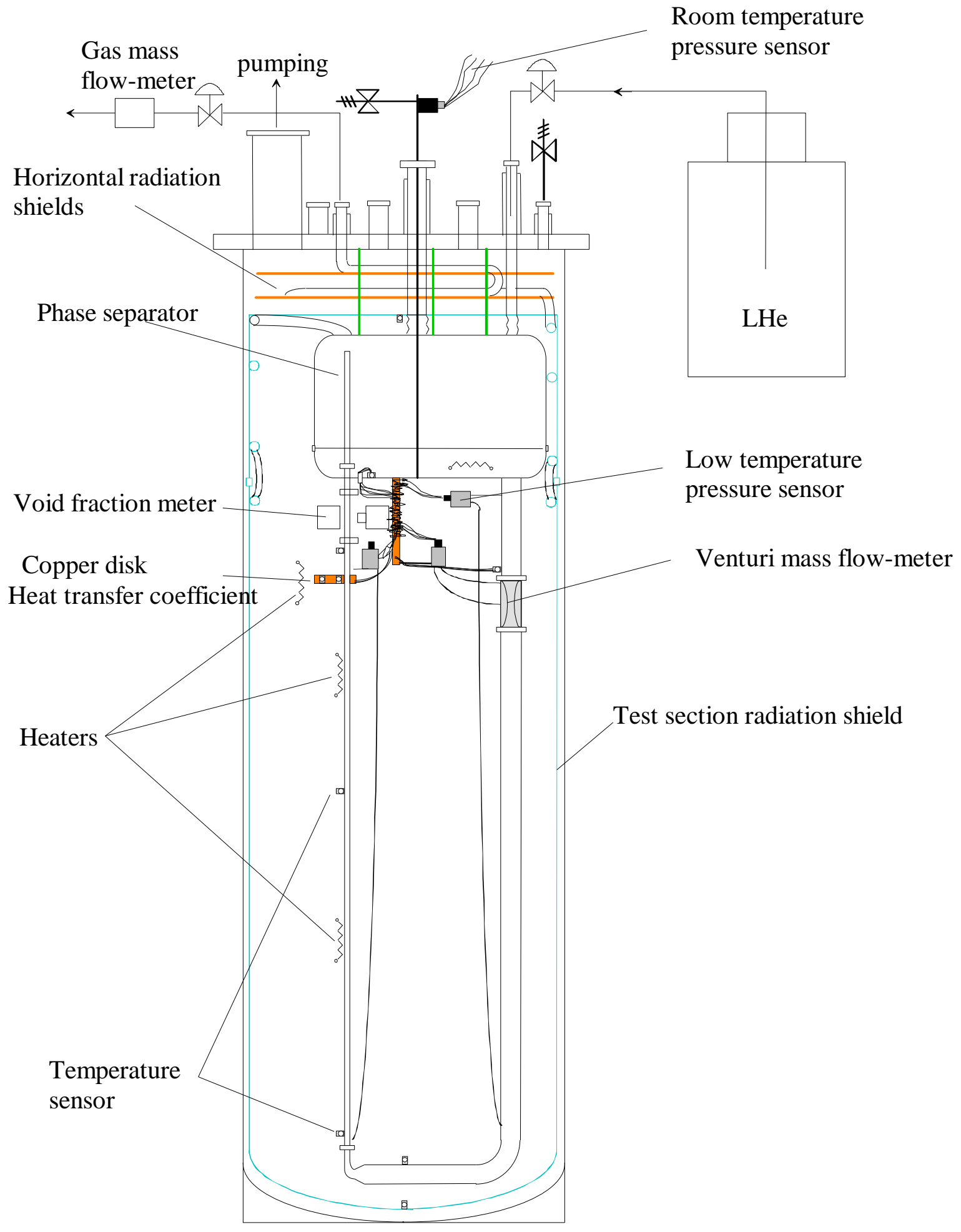

Fig. 1. Schematic of the experimental set-up

\subsubsection{Heat transfer coefficient cell}

The definition of the heat transfer coefficient $h$ is given by,

$\mathrm{h}=\frac{\mathrm{q}}{\mathrm{T}_{\mathrm{w}}-\mathrm{T}_{\mathrm{b}}}$, 
where $q$ is the heat flux density, $T_{w}$ is the wall temperature and $T_{b}$ the bulk fluid temperature of the flow. In order to determine $h$, accurate measurements must be made of the heat transferred, the surface area, the wall temperature and the bulk fluid temperature.

The heat transfer coefficient cell is composed of a $160 \mathrm{~mm}$ in diameter Cual copper disk. The disk is $10 \mathrm{~mm}$ thick for soldering a wire heater around it. The cell is also instrumented with two calibrated germanium sensor located at two different radial position.

Heat is applied to the test copper disk by passing a current through the heater. Since on both side of the copper disk the same value of heat is applied to the copper tube, all the applied heat to the disk is transferred to the flowing He I. The surface area of heat transfer is also known, the geometry of copper disk being well known.

As it is not possible to measure directly the temperature of the tube wall, the thermal conductivity of the copper must be determined by measuring the temperature difference of the two sensors. One can estimated, then, the wall temperature and the temperature of the flow with thermodynamical considerations and so the heat transfer coefficient. A similar method have been used to measured heat transfer coefficient in flowing He II. [1].

\subsubsection{Void fraction measurement}

The principle of measurement is based on the attenuation of electrons energy when going through matter. In two-phase helium, the attenuation of electron energy is higher when they go through liquid than vapor. One can show that the variation of the attenuation of energy is linear with the void fraction of the two-phase fluid. This device has been already successfully used at STCM to measure void fraction in vertical He I two-phase forced flow and it is under development [2].

\section{Acknowledgments}

The author would like to thank P. Ocvirk for helful support, Dr. Bredy for helpful discussions and Dr. Kircher for financial support.

\section{References}

[1] Weisend II JG and Van Sciver SW. Proceedings of Thermophysics and heat transfer, 1990. p. 1-7

[2] Augirond L. Contribution à l'étude des écoulements verticaux d'hélium diphasique.Thèse de doctorat de l'Université Paris VI. Paris.1998. 


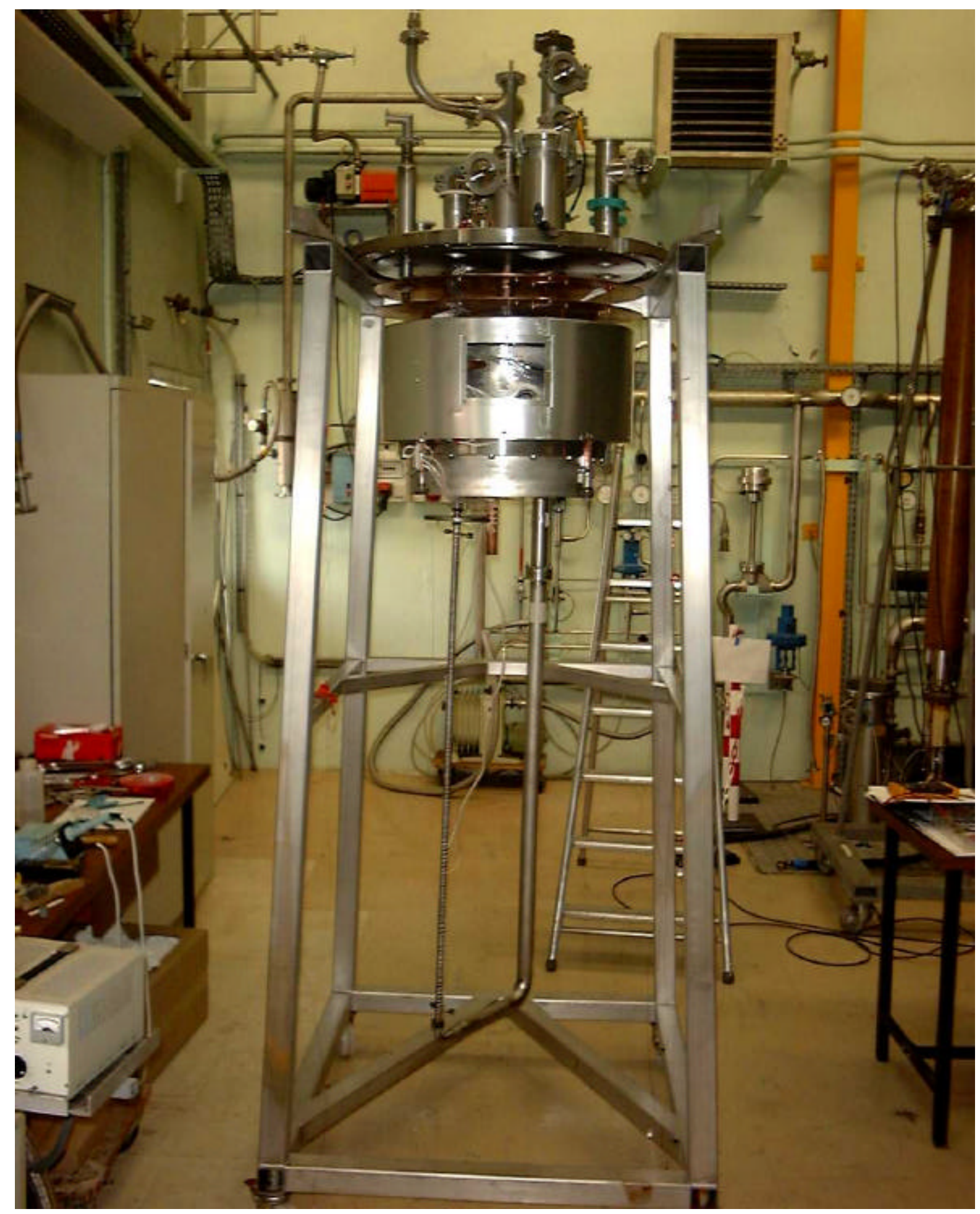

Figure 2. Picture of the experimental facility 